\title{
A FRAGMENTAÇÃO DO PODER E A COMPLEXIDADE DE GOVERNAR NAS REGIÕES METROPOLITANAS
}

\author{
Rodrigo Rage Ferro* \\ Edson Ricardo Saleme* \\ * Unisantos, Direito Ambiental das Cidades, Santos, São Paulo, Brasil.
}

\begin{abstract}
Resumo
Com a maior mobilidade de serviços, capital e pessoas, a questão metropolitana ganha notoriedade. Embora a Constituição já reconhecesse as regiões metropolitanas, foi com o Estatuto da Metrópole, Lei n. 13.089, de 2015, que houve algum avanço em relação à governança interfederativa. Pretendia-se preencher as lacunas e explorar o potencial de diversos instrumentos políticourbanísticos visando à boa governança com base no fomento às iniciativas de cooperação e coordenação federativa, por longas décadas negligenciadas pelo Poder Público. Contudo, a própria fragmentação do poder e a complexidade de governar essas regiões tornam frágeis a gestão e a governança delas, pondo em xeque a viabilidade e a efetividade do Estatuto. Assim, o presente estudo, utilizando o método hipotético-dedutivo, visa analisar algumas inovações trazidas pelo Estatuto ou que deveriam ter sido disciplinadas por ele e o modo como estas se aproximam ou não dos itens essenciais para uma sólida governança e para a superação das fragilidades institucionais.

Palavras-chave

Fragmentação do poder; Complexidade de governar; Governança interfederativa; Regiões metropolitanas; Estatuto da metrópole.
\end{abstract}




\title{
ARTICLES
}

PLANNING AND PUBLIC POLICY

\section{THE FRAGMENTATION OF POWER AND THE COMPLEXITY OF GOVERNING IN THE METROPOLITAN REGIONS}

\author{
Rodrigo Rage Ferro* \\ Edson Ricardo Saleme* \\ * Unisantos, Direito Ambiental das Cidades, Santos, São Paulo, Brazil.
}

\begin{abstract}
As a result of the greater mobility of services, capital andpeople, the metropolitan issue becomes more prominent. Although the Federal Constitution had already recognized the metropolitan regions, it was with the Metropolis Statute, Law n. 13,089/2015, that some progress was achieved in relation to the Brazilian interfederal governance. The government aimed to fill the gaps and explore the potential of several political urban instruments for the production of good governance from the promotion of federative cooperation and coordination initiatives that were neglected by the Public Administration for decades. However, the very fragmentation of power and the complexity of governing these regions make their management and governance fragile and call the viability and the effectiveness of the Metropolis Statute into question. Thus, by using the hypothetico-deductive method, the present research aims to analyze some innovations brought by the Metropolis Statute or that should have been disciplined by it and how they approach or not the essential questions for a solid governance or even in order to overcome the institutional fragilities of these regions.

Keywords

Fragmentation of power; Complexity of governing; Interfederal governance; Metropolitan regions; Metropolis statute.
\end{abstract}




\title{
A FRAGMENTAÇÃO DO PODER E A COMPLEXIDADE DE GOVERNAR NAS REGIÕES METROPOLITANAS
}

\author{
Rodrigo Rage Ferro
}

Edson Ricardo Saleme

\section{Introdução}

Com a globalização e a maior mobilidade de serviços, capital e pessoas que dela resultou, a questão metropolitana assume maior notoriedade no cenário mundial. O intenso contingente populacional e o crescente desenvolvimento econômico dos grandes centros urbanos em todo o planeta provocam um uso mais extensivo do território, principalmente para além dos núcleos das cidades, isto é, a densidade populacional mostra-se maior às margens dos centros urbanos. Ao mesmo tempo, torna-se mais próxima a conexão entre as cidades, sobretudo nas áreas em que a conurbação é um fenômeno mais intenso. Muitas vezes, esse fenômeno resulta na perda do próprio limite territorial da cidade.

No Brasil, a ocupação das periferias é invariavelmente produto de ocupações sem nenhum planejamento. Isso acarreta sérios reflexos nos equipamentos urbanísticos e nos serviços públicos (transporte, saúde, educação, saneamento, entre outros), e o impacto em setores frágeis já se nota de forma imediata. Portanto, verifica-se, cada vez mais, a necessidade de ampliar a infraestrutura básica nessas regiões, a fim de proporcionar melhor qualidade de vida para as pessoas que as ocupam. 
Embora a Constituição Federal de 1988 (BRASIL, 1988) - CF-88 - já reconhecesse regiões metropolitanas (RM)', aglomerações urbanas (AU) e microrregiões ${ }^{2}$, a dificuldade de governar essa realidade dinâmica e complexa exigia uma lei federal que regulamentasse mais efetivamente a questão da governança ${ }^{3}$ e a gestão das diversas tipologias urbanas.

Nesse sentido, um dos grandes avanços em relação ao fenômeno metropolitano ocorreu certamente com o Estatuto da Cidade, estabelecido pela Lei federal $n$. 10.257, de 2001 (BRASIL, 2001), que regulamentou os artigos 182 e 183 da Constituição e que, em seu art. $4^{\circ}$, II, já indicava o planejamento das entidades metropolitanas como um dos importantes instrumentos de política urbana, sobretudo por

1.É importante asseverar que, apesar de o Estatuto da Metrópole (BRASIL, 2015) ser um verdadeiro arcabouço conceitual (PERES, 2018, p. 273), nem sempre ele define com precisão (ou se pode dizer que nem mesmo define) os diversos conceitos envolvidos no fenômeno metropolitano, o que dificulta a instrumentalização política (idem, p. 284). Este artigo, sempre que entender relevante, tentará defini-los com base na doutrina ou no ordenamento jurídico. Prima facie, é importante que se conceitue Região Metropolitana (RM). Para José Afonso da Silva (2017, p. 665), a RM constitui-se de "um conjunto de Municípios cujas sedes se unem com certa continuidade urbana em torno de um Município-polo”. Os critérios historicamente utilizados pelo Instituto Brasileiro de Geografia e Estatística (IBGE) para delimitar as regiões metropolitanas (“continuidade urbana”) são população, atividade e integração (físico-morfológicos). O estudo Região de influência das cidades - Regic, de 2008, realizado pelo IBGE, promoveu uma revisão dos critérios e passou a valorar a funcionalidade, com critérios relativos à classificação dos centros de gestão do território, à intensidade de relacionamentos e à dimensão da região de influência de cada centro e diferenciações regionais. Em 2015, em novo estudo do IBGE, intitulado Arranjos populacionais e concentrações urbanas no Brasil, novos critérios são adotados, como índice de integração baseado na intensidade dos movimentos pendulares para trabalho e estudo, intensidade absoluta dos movimentos pendulares e contiguidade da mancha urbana (PERES, 2018, p. 279). SILVA, J. A. da. Curso de Direito Constitucional Positivo. 25. ed. São Paulo: Malheiros, 2017. IBGE. Região de influência das cidades - Regic. Rio de Janeiro: IBGE, 2008. Disponível em: https://www.mma.gov.br/estruturas/PZEE/_arquivos/ regic_28.pdf. Acesso em: 30 jan. 2020. IBGE. Arranjos populacionais e concentrações urbanas no Brasil. 2. ed. Rio de Janeiro: IBGE, 2015. Disponível em: https://biblioteca.ibge.gov.br/visualizacao/livros/liv9970o. pdf. Acesso em: 30 jan. 2020.

2. Para José Afonso da Silva (2017, p. 665), citado em nota explicativa anterior, microrregiões são formadas por "grupos de Municípios limítrofes com certa homogeneidade e problemas administrativos comuns, cujas sedes não sejam unidas por continuidade urbana”. Finalmente, aglomerações urbanas (AU) são "áreas urbanas sem um polo de atração urbana”, sejam áreas que envolvam sedes dos municípios ou não. O enfoque deste artigo recai sobre as regiões metropolitanas, por se tratar do caso mais comum e por ser o termo mais utilizado na doutrina jurídica e no ordenamento jurídico no que diz respeito às entidades metropolitanas de maneira geral.

3. A governança interfederativa está relacionada à forma como se administra a região metropolitana. De acordo com o art. 20, IV, do Estatuto da Metrópole (BRASIL, 2015), governança interfederativa é o "compartilhamento de responsabilidades e ações entre entes da Federação em termos de organização, planejamento e execução de funções públicas de interesse comum”. Além disso, de acordo com art. $8^{\circ}$ do Estatuto (BRASIL, 2015), em sua estrutura básica estão compreendidos uma instância executiva composta dos representantes do Poder Executivo dos entes federativos integrantes, uma instância colegiada deliberativa com representação da sociedade civil, uma organização pública com funções técnico-consultivas e um sistema integrado de alocação de recursos e de prestação de contas. 
qualificar o nível regional como necessário para o atendimento às carências de infraestrutura da população envolvida.

Contudo, foi com a sanção do Estatuto da Metrópole, em janeiro de 2015, pela Lei n. 13.089, de 2015 (BRASIL, 2015), que a governança interfederativa ganhou o devido destaque no cenário brasileiro.

De fato, esse estatuto reforçou a importância da governança interfederativa como forma de coordenação e gestão entre Estado ou estados e municípios conurbados, disciplinada de modo geral no Estatuto da Metrópole, na Lei Complementar e nos futuros planos de desenvolvimento urbano integrado, com vistas a propiciar uma maneira melhor de gerir os problemas advindos da falta de serviços públicos, especificamente as funções públicas de interesse comum (FPICs) ${ }^{4}$, invariavelmente consignadas na lei complementar criadora, além de maior integração econômica, política e cultural dentro da região metropolitana. Segundo Marguti (2014, p. 15), as FPICs são funções que se destinam ao desenvolvimento regional, como, por exemplo, transporte, saneamento básico e uso do solo.

$\mathrm{O}$ objetivo era preencher as lacunas e explorar o potencial de diversos instrumentos político-urbanísticos para a produção da boa governança, valendo-se do fomento às iniciativas de cooperação e coordenação federativa, negligenciadas por longas décadas pelo Poder Público.

Embora o Estatuto da Metrópole não defina critérios para julgar quão adequada é a governança interfederativa, ele dispõe os princípios e as diretrizes ${ }^{5}$ a serem observados, respectivamente em seus artigos $6^{\circ}$ e $7^{\circ}$ e art. $7^{\circ}$-A, este último incluído pela Lei n. 13.683, de 2018 (BRASIL, 2018). Entre os princípios, destacam-se a prevalência do interesse comum sobre o local; o compartilhamento de responsabilidades e de gestão para a promoção do desenvolvimento urbano integrado; a autonomia dos entes da federação; a observância das peculiaridades regionais e locais; a gestão democrática da cidade; a efetividade no uso dos recursos públicos e a busca do desenvolvimento sustentável.

Maria do Livramento Miranda Clementino (2018, p. 379), ao comentar a implementação do Estatuto da Metrópole na Região Metropolitana de Natal, tem o

4. A designação das FPICs está no inciso II do art. $2^{\circ}$ do Estatuto da Metrópole (BRASIL, 2015); elas consistem na "política pública ou ação nela inserida cuja realização por parte de um Município, isoladamente, seja inviável ou cause impacto em Municípios limítrofes”. Em geral, são serviços públicos comuns a serem prestados pelos entes federativos integrantes da RM, os quais devem estar previstos nas leis complementares estaduais que instituam a RM.

5. É importante explicitar que também se devem observar as diretrizes do art. $2^{\circ}$ do Estatuto da Cidade (BRASIL, 2001), o que mostra que o Estatuto da Metrópole está em sintonia com a necessidade de compatibilização dos planejamentos urbanos dos municípios envolvidos com o regional (da região metropolitana) e com os setoriais. 
entendimento de que uma boa governança requer a integração das políticas públicas de escopo mais abrangente, como as territoriais, por meio da superação de entraves ao desenvolvimento dos municípios integrantes, exemplificados pela "fragilidade ambiental, a desigualdade socioeconômica e a desarticulação política”.

Com razão, a própria fragmentação do poder e a complexidade de governar essas regiões ainda estão evidentes quando se analisa o cenário político-jurídico dessas localidades ${ }^{6}$. Existem uma fragilidade e uma fragmentação institucional no que se refere à gestão e à governança dessas regiões que, com frequência, põem em xeque a viabilidade e a efetividade das normas que preconizam sua criação e a própria finalidade do Estatuto da Metrópole.

De fato, os arranjos institucionais e as articulações entre as cidades requerem mecanismos que valorizem a identidade e que reforcem as especificidades de cada região. São necessários instrumentos capazes de vencer a histórica fragilidade dos mecanismos de cooperação e coordenação federativa; de lidar e conduzir o complexo sistema político metropolitano, conformando os diversos interesses em jogo - dos governos municipais, estaduais, federal, da sociedade civil e do próprio mercado -, e, principalmente, de buscar uma maneira de se adaptar à figura da região metropolitana dentro do contexto federativo consolidado pela CF-88.

Vale ressaltar que o chamado "Plano Diretor", previsto no art. 82 da CF-88 (BRASIL, 1988) e no Estatuto da Cidade (BRASIL, 2001), isoladamente e entregue de forma compartimentalizada aos municípios, não conseguiu até hoje concretizar de maneira efetiva os direitos sociais e as funções sociais da cidade e da propriedade urbana (BONIZZATO, 2015, p. 1868). Ademais, para piorar a insegurança jurídica e a inefetividade dos planos diretores, na região onde vários municípios se findam e formam uma conurbação, como nas RMs, a articulação entre os planos diretores dos municípios envolvidos é mínima ou nem sequer é constatável, tornando a RM em questão carente de um planejamento urbano integrado e minimamente adequado. Desse modo, a existência de um plano urbanístico hierarquicamente superior, capaz de dialogar com os vários planos diretores envolvidos, é fundamental para o desenvolvimento urbano do país (idem, p. 1871).

\footnotetext{
6. É relevante apontar que, a princípio, a fragmentação do poder em si não é um problema, porém se torna um quando conjugada a outros fatores, como a fragilidade institucional histórica das RMs no Brasil. Essa situação se agrava, conforme será visto ao longo deste artigo, quando se tem uma governança interfederativa ainda muito incipiente, baseada na coordenação e na cooperação entre os entes envolvidos. É nesse sentido que o artigo se mostra esclarecedor, uma vez que fragmentar o poder, compartimentalizando-o, sem a devida articulação ou gestão integrada, torna mais complexo o ato de governar as RMs, principalmente na execução das FPICs e na compatibilização entre os planos diretores e setoriais.
} 
Esse problema ocorre igualmente em diversos países da América Latina, como México e Argentina, onde a concentração metropolitana e a ampliação da liderança de suas metrópoles, dentro das regiões metropolitanas, fizeram com que o Poder Público não conseguisse implementar políticas metropolitanas para além das escalas municipais, prevalecendo uma política de forma bem compartimentada e com difícil gestão integrada (ONU-HABITAT, 2012, p. 14).

Também é relevante asseverar que, embora não se constitua, assim como ocorre no México, um novo ente federativo7, a região metropolitana no Brasil conforma um novo tipo de ente administrativo passível de se tornar objeto de políticas públicas, em que a administração dos problemas regionais, a promoção do desenvolvimento socioeconômico em arranjos metropolitanos e o desempenho adequado das funções públicas de interesse comum são essenciais para o bem comum de seus habitantes. Além disso, a emergência do "metropolitano" revela importantes desafios, sobretudo no que diz respeito à formulação das políticas públicas e à necessidade de articulação entre os entes federativos envolvidos.

Portanto, a grande questão a que se pretende responder aqui é: como superar a fragilidade institucional das regiões metropolitanas se a fragmentação do poder e a complexidade de governar as respectivas regiões fazem parte historicamente do cenário político brasileiro, marcado por uma política bem compartimentada e de difícil integração entre os entes federativos?

Nesse contexto, o presente estudo, utilizando o método hipotético-dedutivo, com o apontamento de experiências ocorridas nas diversas regiões metropolitanas brasileiras e no direito comparado, e também a metodologia bibliográfica, tem a finalidade de analisar algumas inovações trazidas pelo Estatuto, ou que deveriam ter sido disciplinadas, e o modo como elas se aproximam ou não dos itens considerados essenciais para uma governança sólida e para a superação das fragilidades institucionais dessas regiões.

Tendo em vista esse objetivo, o artigo foi estruturado em duas etapas: a primeira parte do artigo traça um breve histórico da questão metropolitana e do contexto federativo no Brasil, ao passo que a segunda se concentra na questão da

\footnotetext{
7. No México e no Brasil, há regras que proíbem a criação de níveis intermediários de governo entre o município e o estado (como um governo metropolitano), o que dificulta o fortalecimento da RM. No caso da Argentina, além de a RM não ser um ente político, a Constituição atribui às províncias o direito de definir o regime municipal, o que prejudica ainda mais a governança metropolitana, uma vez que proliferam os sistemas municipais, com difícil compatibilização (ROJAS, 2008, p. 7-8). Em países como Estados Unidos e Canadá, são os próprios “governos estaduais e provinciais”, e não o governo central, que "facilitam a concessão de poderes aos governos locais (empoderamento) para enfrentar os desafios metropolitanos", conforme explicitam Wilson et al. (2011, p. 29). WILSON, R. H.; SPINK, P. K.; WARD, P. M. Governança metropolitana nas Américas. Caderno Metrópoles, v. 13, n. 25. São Paulo, jan.jun. 2011, p.15-44. Disponível em: https://revistas.pucsp.br/metropole/article/view/5980. Acesso em: 28 jan. 2020.
} 
fragmentação do poder e da complexidade de governar, ou seja, de administrar essas áreas, e no modo como uma boa governança interfederativa poderia ajudar a superar a fragilidade institucional dessas regiões.

\section{O fenômeno metropolitano brasileiro: um breve histórico de sua formação}

De forma tecnocrática e top-down, a Constituição de 1967 outorgou à União a competência para a criação de regiões metropolitanas, de modo que o conceito de "região metropolitana” passou a ser objeto de uma definição legal (BRASIL, 1967). 0 entendimento era, então, de que o fenômeno metropolitano constituía uma questão nacional (PERES, 2018, p. 269).

Também não se pode deixar de observar que havia uma preocupação por parte do governo da época com a organização das regiões metropolitanas com o intuito de propiciar os objetivos estratégicos de desenvolvimento econômico; inclusive, a matéria metropolitana era tratada, no art. 164 da Emenda Constitucional n. 1, de 1969 (BRASIL, 1969), como disposição da Ordem Econômica (ALVES, 2001). Portanto, havia maior enfoque em normatizar a atuação do Estado do que necessariamente em compreender o fenômeno metropolitano (PERES, 2018, p. 269).

A primeira tentativa de estruturação nacional da agenda metropolitana, ainda durante o regime militar, não buscava atender às demandas por coordenação e cooperação interfederativa. Com efeito, alicerçada em uma sociedade com forte tendência de se concentrar nos grandes centros urbanos, visava estabelecer a integração do território brasileiro forjada na inter-relação entre as unidades políticas, de forma que a administração fosse altamente centralizada, com reduzido poder decisório para as bases locais (OLIVEIRA, 2015, p. 631).

Para alguns, essa primeira institucionalização das regiões metropolitanas foi imposta sobre estados e municípios pelo governo federal como um instrumento adicional de dominação da União, como forma de poder exercer um controle mais direto sobre a distribuição de recursos para essas áreas, na tentativa de amortecer as tensões sociais crescentes nos principais centros urbanos do país (GUIA, 2006).

Inicialmente, a Lei Complementar n. 14, de 1973 (BRASIL, 1973), criou, com base na Constituição de 1967-69, as regiões metropolitanas de São Paulo, Belo Horizonte, Porto Alegre, Salvador, Curitiba, Belém e Fortaleza. Além disso, permitiu a unificação da execução de serviços comuns, mediante a autorização da concessão de serviços a entidades estatais, a constituição de empresas no âmbito metropolitano e ainda a confecção de convênios (CÉSAR, 2017, p. 143-144).

Apesar de não atribuir receita autônoma às regiões metropolitanas, essa lei complementar assegurou preferência aos municípios metropolitanos na obtenção de recursos federais e estaduais (HORTA, 1975), o que corrobora o aspecto de 
dominação e controle exercidos pela União, bem como o esvaziamento político e tributário da importância dos munícipios anteriormente citados.

Em virtude desse aspecto hierárquico e top-down também na Constituição vigente, a questão metropolitana não foi vista pela Constituinte como assunto prioritário. Guia (2006) afirma que, “ao contrário, como a institucionalização metropolitana vigente encontrava-se profundamente atrelada ao esvaziamento dos municípios e a ranços anteriores do período militar, tudo apontava para uma não política federal em relação ao tema”.

Nessa toada, percebe-se que a CF-88, reforçando o seu caráter municipalista, com maior autonomia para os municípios, descentralizador e de resistência em priorizar a questão metropolitana (MACHADO, 2007, p. 67), deu tratamento genérico às regiões metropolitanas, uma vez que delegou aos estados a maioria das definições de suas atribuições, antes concentradas na União (CÉSAR, 2017), mas evitando disciplinar mais detalhadamente as regiões metropolitanas e suas funções. Esse tema era associado ao autoritarismo e à centralização da administração pública ocorridos no regime militar (PERES, 2018, p. 271) ${ }^{8}$.

De fato, apenas é previsto, no seu art. $25, \S 3^{\circ}$ (BRASIL, 1988), que cabe aos estados federados a competência para instituir regiões metropolitanas mediante lei complementar, de forma a "integrar a organização, o planejamento e a execução de funções públicas de interesse comum”. É relevante sublinhar que, em comparação com a Constituição anterior, houve o deslocamento desse tema para o capítulo referente à Organização do Estado, o que demonstra o objetivo do constituinte originário de tratar esse tema dentro da estrutura organizacional e administrativa do Estado brasileiro (SANTOS, 2006), isto é, em caráter administrativo intergovernamental, e não mais restrito à ordem econômica, como no período militar.

\footnotetext{
8. É relevante dizer que não é só no Brasil que as regiões metropolitanas sofrem com o problema da expansão territorial e as deficiências de infraestrutura. Em diversos países latino-americanos, os desafios metropolitanos para o combate à pobreza e à segregação socioespacial também estão presentes. Adicionalmente, por muito tempo o fortalecimento do poder local na América Latina, em certa medida parecido com o que ocorre no Brasil, foi visto como uma conquista democrática, em detrimento de um fortalecimento institucional em nível metropolitano, associado a padrões centralistas e autoritários (FREY, 2012, p. 9o). Essa omissão, em termos de um arranjo institucionalizado em nível metropolitano, resultou em regiões metropolitanas da América Latina carentes de uma governança metropolitana capaz de "criar competitividade urbana, sustentabilidade ambiental e melhor qualidade de vida" (KLINK, 2005, p. 176). Segundo Klink (p. 171, apud ROJAS et al., 2005), exceções à ausência de uma governabilidade metropolitana são, entre outras, representadas pelas cidades de Quito e Bogotá. No caso da RM de Quito, Rojas (2008, p. 8) destaca que "a forte tradição de um governo local eficiente" e "a quase completa equivalência entre os territórios da aglomeração metropolitana e aqueles sob jurisdição do município" facilitaram a boa gestão metropolitana. KLINK, J. Perspectivas recientes sobre la organización metropolitana: funciones y governabilidad. In: ROJAS, E.; CUADRADO-ROURA, J. R.; GÜELL, J. M. F. (orgs.). Gobernar las metrópolis. Washington D.C.: Banco Interamericano de Desarollo, Universidad de Alcalá de Henares, 2005, p.127-191. Disponível em: https:/publications.iadb.org/publications/spanish/document/ Gobernar-las-metr\%C3\%B3polis.pdf. Acesso em: 15 abr. 2020.
} 
É preciso destacar que a disposição constitucional referente à criação das regiões metropolitanas, apesar de sua natureza organizacional, não autorizou a criação de ente político-administrativo interfederativo com autonomia e capacidade de auto-organização, com poderes legislativos próprios e de autogoverno. Não se quis criar mais um ente federativo com organização própria e eleição de representantes, além da capacidade de autoadministração, com organização e prestação de serviços públicos independentemente dos entes federativos. Portanto, a região metropolitana não é um novo ente federativo, mas é constituída por meio de um corpo jurídico-administrativo territorial em forma de autarquia territorial, intergovernamental e plurifuncional (ALVES, 2001).

Diante da adoção do federalismo de cooperação e integração da CF-88, especialmente em relação à forma de planejamento, programação, execução e controle de funções estatais e de serviços públicos de caráter urbano-regional, bem como de interesse comum por diversas entidades governamentais, nela não se prevê uma distribuição de competências de modo estanque e compartimentado, e sim um partilhamento de competências normativas e administrativas de maior flexibilidade e agilidade para que a ação mais adequada e racional seja levada a cabo pelo Poder Público, em que se observa a predominância do interesse como princípio maior (ALVES, 2001).

Para Luís Roberto Barroso (2007), a noção de predominância implica um conceito dinâmico ao longo do tempo e da evolução dos fenômenos sociais, de forma que o que hoje seria um interesse predominantemente local pode, no futuro, ser de predominância regional.

O próprio Supremo Tribunal Federal (STF) não esclarece com precisão no que consiste o princípio da predominância do interesse. Esse fator, em muitas ocasiões, gera dúvida a respeito de sua existência ou não em situações determinadas. E a situação se agrava ainda mais quando estão presentes interesses locais e regionais, a exemplo de municípios reunidos em unidades metropolitanas em que os interesses não se limitam territorialmente a um deles, mas a repercussão se apresenta externa a eles.

Outrossim, com a disposição existente no texto do $\S 3^{\circ}$ do art. 25 da CF-88 (BRASIL, 1988), inaugura-se uma nova e significativa dimensão do federalismo de integração. Esses fatos provocaram o aumento do número de regiões metropolitanas com vistas a atender à intensificação dos processos de urbanização e de metropolização do território nacional (PERES, 2018, p. 268), porém com governanças não muito bem definidas, além de fraca integração entre os municípios e poucos recursos financeiros. Em geral, a formação de tais regiões tinha por finalidade garantir 
alguma vantagem fiscal ou financeira para os municípios integrantes e somenos objetivava a "captação do fenômeno metropolitano" (SANT’ANA, 2016, p. 98).

Diante disso, não parece lógico realizar simplesmente por lei complementar estadual a integração compulsória dos municípios com o propósito de realizar as funções públicas de interesse comum em casos em que a conexão entre os municípios não seja tão forte, sob pena de interferir e comprometer a autonomia dos municípios envolvidos.

Com efeito, ao mesmo tempo que a complexidade que envolve o conceito de autonomia dos entes político-administrativos em regiões metropolitanas é ampliada, há uma exigência natural de articulação, coordenação e integração de atividades e ações públicas municipais, estaduais e federais por meio de uma forma institucional adequada para a eficácia e a eficiência na prestação de funções públicas de interesse comum nessas regiões. Portanto, os interesses metropolitanos não podem estar restritos a um ente federativo específico, sob pena de haver graves prejuízos para a gestão das funções públicas de interesse comum, nem serem delegados à própria região metropolitana. Na verdade, eles devem ser geridos com eficiência para viabilizar, de certo modo, como deduzem Marco Aurélio Costa e Isadora Tami Lemos Tsukumo (2013), um grau mais favorável à promoção do crescimento econômico capitaneado pelo Poder Público.

Também essa é a proposta colombiana para a criação de regiões metropolitanas. Segundo escólio de Óscar A. Alfonso Roa (2017), as regiões metropolitanas na Colômbia gozam de uma capacidade intrínseca para promover níveis de autonomia mais elevados e, com isso, lograr a liberação do crescimento econômico, de equilíbrio social, de reprodução ecológica natural e de um modelo mais moderno de gestão.

Nesse diapasão, começaram a ser questionadas as condições de participação dos municípios metropolitanos nas decisões regionais, assim como no processo de normatização, controle e gestão das funções públicas de interesse comum (ALVES, 2001), e a própria titularidade dessas funções - por exemplo, as de saneamento, habitação, mobilidade urbana, limpeza de vias e manutenção e preservação de recursos hídricos, entre outras -, uma vez que não havia uma lei federal disciplinando critérios e balizamentos para a aplicação do art. 25, $§ 3^{\circ}$, da CF-88 (BRASIL, 1988).

Nessa toada, o STF, na Ação Direta de Inconstitucionalidade (ADI) 1842/RJ, julgou a constitucionalidade de dispositivos das leis que criaram a Região Metropolitana do Rio de Janeiro e a Microrregião dos Lagos e analisou o arranjo institucional para a prestação dos serviços de saneamento em ambas. 
Naquela ocasião, a Corte reconheceu como poder concedente e titular do serviço público de interesse comum de saneamento o colegiado formado pelos municípios e pelo respectivo estado, uma vez que "a participação dos entes nesse colegiado não necessita ser paritária, desde que apta a prevenir a concentração do poder decisório no âmbito de um único ente”.

Segundo o voto do ministro Gilmar Mendes, caso o poder decisório se concentrasse no estado, "tal fato eliminaria, neste aspecto, a capacidade de autoadministração dos municípios envolvidos e consequentemente o núcleo essencial da autonomia municipal”. Também não poderia concentrar-se nos municípios envolvidos, já que "o interesse comum é muito mais que a soma de cada interesse local envolvido, pois a má condição da função de saneamento básico por apenas um município pode colocar em risco todo o esforço do conjunto, além das consequências para a saúde pública de toda a região”. O próprio ministro Gilmar Mendes defende que a função pública de saneamento frequentemente extrapola o interesse local e passa a apresentar natureza de interesse comum.

O STF acrescentou que "a participação de cada Município e do Estado deve ser estipulada em cada região metropolitana de acordo com suas particularidades, sem que se permita que um ente tenha predomínio absoluto”. Portanto, deve-se estruturar uma solução compartilhada entre os municípios e o estado para a prestação dos serviços de interesse comum em regiões metropolitanas, aglomerações urbanas e microrregiões, preservando o autogoverno e a autoadministração dos municípios em foco.

A partir desse julgado, fica claro que o estado cria e organiza a entidade administrativa pública, mediante lei complementar, mas não pode restringir a participação dos municípios metropolitanos na gestão dos assuntos regionais. Em face disso, os representantes do estado e dos municípios envolvidos deverão, de forma não necessariamente paritária (e observadas as peculiaridades de cada caso), participar das funções normativas, diretivas e administrativas correspondentes. Destarte, deve haver uma cooperação mútua entre os níveis de governo, tanto horizontalmente (entre municípios da mesma região) como verticalmente (entre estado e municípios) (ALVES, 2001).

Nesse sentido, a edição do Estatuto da Metrópole correspondeu a um avanço, pois nele se estabeleceram as diretrizes gerais para o planejamento, a gestão e a execução de funções públicas de interesse comum em regiões metropolitanas e aglomerações urbanas instituídas pelos estados, além de normas gerais sobre o plano de desenvolvimento urbano integrado. Ainda, ele explicita diversos instrumentos de governança interfederativa e critérios para o apoio da União a ações que envolvam essa governança no campo do desenvolvimento urbano (CÉSAR, 2017, 
p. 148) com base no conceito de gestão plena. Assim, o Estatuto busca fomentar a cooperação entre os entes para possibilitar uma prestação adequada das funções públicas de interesse comum.

O Estatuto da Metrópole trouxe inovações no campo da gestão e da governança metropolitana, contudo o grande destaque foi o conceito de gestão plena (OLIVEIRA, 2015, p. 637). Para que isso se concretize, a lei (art. $2^{\circ}$, inc. III) (BRASIL, 2015) exige (i) a formalização e a delimitação da região metropolitana por meio de lei complementar estadual; (ii) estrutura de governança interfederativa própria; e (iii) plano de desenvolvimento urbano integrado aprovado por lei estadual. Dessa forma, seria possível o acesso a recursos federais para a execução de projetos de cunho metropolitano. Ademais, o Estatuto excluiu do arranjo de governança interfederativa (no caso da região metropolitana) o principal ator de financiamento de políticas públicas no país: a União (SANT’ANA, 2016, p. 115).

Algumas mudanças em relação à governança interfederativa foram promovidas pelo Estatuto. De acordo com o seu art. $8^{\circ}$ (BRASIL, 2015), a governança interfederativa das regiões metropolitanas compreenderá uma instância executiva, uma instância colegiada deliberativa com representação da sociedade civil, uma organização pública com funções técnico-consultivas e um sistema integrado de alocação de recursos e de prestação de contas. Portanto, a gestão democrática estará presente na instância deliberativa, sem, no entanto, a lei determinar como ocorrerá a participação da sociedade civil (OLIVEIRA, 2015, p. 637).

A gestão metropolitana, com efeito, sempre foi tema complexo em decorrência da inexistência de uma legislação federal específica. Mesmo após a edição do Estatuto da Metrópole, parece não haver ainda estruturas muito consistentes relacionadas à gestão metropolitana, exceto com relação às FPICs, uma vez que nenhuma lei complementar de criação deixou de esclarecer quais são essas funções (COSTA et al., 2018, p. 31). Conforme esse autor e colaboradores (2018, p. 31), poucas leis "estabelecem a criação de um sistema de gestão adequado à complexidade da gestão compartilhada ou instituem conselhos específicos e, em sua maioria, são omissas no endereçamento da questão do financiamento e desenvolvimento metropolitano".

Relativamente ao plano de desenvolvimento urbano integrado (PDUI), a Lei n. 13.089, de 2015 (BRASIL, 2015), impõe o dever de o instituir por lei estadual e revisá-lo, pelo menos, a cada dez anos. Adicionalmente, os planos diretores dos municípios participantes da região metropolitana devem ser compatibilizados com as diretrizes do PDUI (art. 10, $\S 3^{\circ}$ ), viabilizando, dessa forma, um planejamento integrado em toda a região e cumprindo uma exigência importante para a gestão integrada na região metropolitana (OLIVEIRA, 2015, p. 638). Destarte, são inúmeras 
as funções de interesse comum que necessitam ser "articuladas entre as cidades nas regiões metropolitanas, sendo interessante a adequação dos instrumentos legais referentes a tais funções ao PDUI” (OLIVEIRA, 2015, p. 639).

Edson Ricardo Saleme e José Marques Carriço (2018, p. 74) afirmam que o "PDUI estabelece diretrizes, projetos e ações para que se oriente o desenvolvimento urbano e regional, com o fim de buscar melhorar as condições de vida da população metropolitana, reduzindo, na medida do possível, as desigualdades”.

Sintetizando, o Estatuto da Metrópole contribuiu para: (i) esclarecer conceitos; (ii) estabelecer critérios para a constituição de RM e AU; (iii) estabelecer meios de controle social dessas unidades; (iv) apontar instrumentos de desenvolvimento urbano integrado, com destaque para o Plano de Desenvolvimento Urbano Integrado; (v) sistematizar a estrutura de governança interfederativa das unidades regionais; (vi) criar o conceito e os requisitos para a chamada "gestão plena”; e (vii) fixar critérios para o apoio da União a ações que envolvam a governança interfederativa no campo do desenvolvimento urbano (SCHIRATO, 2016).

Apesar de alguns avanços obtidos com a edição do Estatuto, ainda se constatam fragilidade da gestão e fraca cooperação dos entes envolvidos na região metropolitana (OLIVEIRA, 2015, p. 641).

De fato, com a CF-88, a gestão foi descentralizada, mas a fragmentação do poder e a complexidade de governar fazem parte do cenário político-jurídico das regiões metropolitanas brasileiras. Isso, somado com algumas omissões do Estatuto, como a falta de garantia de disponibilidade adequada de recursos financeiros para arcar com funções públicas de interesses comuns de tamanha complexidade, acaba por não contribuir decisivamente para superar essa fragilidade institucional das regiões metropolitanas e a fraca articulação entre os entes federativos, conforme será visto em seguida. Diante disso, tornam-se necessários novos mecanismos capazes de corroborar uma gestão plena e uma boa governança interfederativa entre os entes envolvidos.

\section{A fragmentação do poder, a complexidade de governar e a fragilidade} institucional das RMs

Com a CF-88, houve elevação dos encargos e responsabilidades com políticas públicas e na prestação de serviços públicos, como educação, saúde e saneamento, por parte dos estados e municípios. Ocorre uma "redistribuição de recursos e de responsabilidades entre os três níveis de governo com a ênfase no municipalismo", o que provoca maior fragmentação dos processos de tomada de decisões e torna mais complexa a gestão das funções públicas (CÉSAR, 2017). Ademais, conforme visto anteriormente, as funções públicas de interesse comum devem ser geridas de 
forma compartilhada entre diferentes entes públicos autônomos, o que acaba por complexificar a tarefa de coordenação.

Para tentar superar essa fragmentação do poder, realizada sem as precauções voltadas para uma gestão integrada, e a própria complexidade de governar, o Poder Público instaura uma região metropolitana. Na prática, porém, permanecem a falta de critério objetivo na criação das RM, baixa cooperação entre os entes federativos - e isso evidencia a dificuldade da descentralização no país (BRUNO, 2016, p. 259) - e a reduzida disponibilidade de recursos financeiros, reforçando a fragilidade institucional das regiões metropolitanas brasileiras (OLIVEIRA, 2015, p. 642). Percebe-se também falta de maturidade política para lidar com o fenômeno metropolitano quando o ente de maior capacidade financeira entra em conflito político por ter de contribuir com investimentos mais vultosos para tratar de determinadas FPICs em detrimento daquele de menor capacidade, uma vez que esse fato é comum no formato de governança estabelecido pelo Estatuto, ao fomentar a solidariedade e a cooperação para obter maior eficiência (OLIVEIRA, 2015, p. 642).

Corroborando esse quadro de fragilidade institucional, a RM não possui capacidade normativa e, considerando que as funções públicas requerem regulamentação por lei, é preciso "estabelecer um condomínio legislativo para alcançar a unidade necessária objetivando a organização, o planejamento e a execução das funções públicas” (ALVES, 2001), o que torna hercúleo o esforço para resolver essa empreitada. Além disso, o Estatuto da Metrópole exige a compatibilização de diferentes planos diretores municipais com o PDUI, o que torna a tarefa ainda mais complexa, em razão da necessidade de "observância de planos, programas e prioridades estabelecidos a nível regional” (ALVES, 2001).

Um exemplo que ilustra bem essa situação é dado pelo Rio de Janeiro. Como afirmam Vicente Loureiro e Vera França e Leite (2018, p. 263), a discussão pela aprovação de um PDUI gerou algumas resistências por conta do "receio de perda de autonomia do poder local”, mas, cada vez mais, chega-se à conclusão de que não se pode esquecer de que já há uma “consciência metropolitana irreversível”, a fim de viabilizar um ambiente de melhor qualidade de vida aos munícipes "no espaço territorial urbano-metropolitano”. Portanto, não há mais como menosprezar esse aspecto, e os debates na Assembleia Legislativa do Estado do Rio de Janeiro (Alerj) sobre a questão da governança federativa são certamente fundamentais para o enriquecimento da proposta do planejamento.

Apesar disso, não se pode deixar de obtemperar que a cooperação entre os entes federativos nem sempre é estimulada pela descentralização, visto que, constantemente, há disputas pelas receitas fiscais (guerra fiscal). A falta de recursos financeiros, por sua vez, é crescentemente percebida à proporção que se verifica 
a ocupação desordenada das periferias das grandes cidades e, como decorrência, aumenta a demanda por serviços públicos essenciais.

O processo de crescimento urbano, principalmente nos casos de conurbação, em que a concentração da população urbana nas áreas metropolitanas e em aglomerações urbanas reforça os desequilíbrios de redes de cidades (SANTOS, 2006), gera significativo aumento nas demandas sobre (i) os sistemas de infraestrutura (energia e iluminação pública, água e esgoto, drenagem urbana, entre outros); (ii) os serviços urbanos (saúde, educação, segurança, entre outros); (iii) equipamentos públicos e coletivos; (iv) a ampla gama de políticas setoriais (habitação e mobilidade urbana, por exemplo) (SANT’ANA, 2016, p. 96), além de acarretar problemas de sustentabilidade. São esses os fatores que tornam essas unidades ainda mais dependentes de recursos e repasses da União ou dos próprios entes federativos que compartilham sua gestão.

Para corroborar esse pensamento, vale mencionar a experiência da RM de Santiago, no Chile, que mostra que a atribuição eficiente e bem definida de responsabilidades e recursos para as várias esferas de governo é extremamente importante. Aos governos municipais integrantes da RM, cabem, entre outros serviços públicos essenciais, a remoção de resíduos sólidos e o uso e planejamento do solo. O governo regional (nível entre o munícipio e o governo central) é responsável por financiar os investimentos municipais e setoriais nas RM (ROJAS, 2008, p. 9), ao passo que os serviços públicos críticos metropolitanos, como água e esgoto, são financiados por serviços de utilidade pública privados, embora regulados pelo governo central (idem, ibidem).

É preciso salientar também que, apesar de o fundo ser um facilitador para a concretização da gestão metropolitana (OLIVEIRA, 2015, p. 645), o Fundo Nacional de Desenvolvimento Urbano Integrado (FNDUI), de grande capacidade, previsto na lei (BRASIL, 2015), que visava apoiar ações de governança interfederativa em regiões metropolitanas, foi objeto de veto da Presidência da República, restando ao desenvolvimento urbano integrado em caso de gestão plena apenas o apoio da União (que, de forma desarrazoada, foi excluída do processo direto de gestão das regiões metropolitanas, o que resultou na ausência de nível nacional na governança interfederativa). Entre os argumentos, destaca-se que o fundo cristalizaria "a vinculação a finalidades específicas, em detrimento da dinâmica intertemporal de prioridades políticas”. Isso, apesar de ser verdade, compromete muito o bom andamento da gestão das funções públicas de interesse comum, uma vez que os repasses nem sempre são constantes e dependem sobremaneira do auxílio da iniciativa privada - o que, com frequência, sem fiscalização eficiente e regulação forte, pode acabar cooptando o Poder Público (OLIVEIRA, 2015, p. 643). 
Também não se pode deixar de observar um elemento que reitera essa fragilidade institucional: a falta de um aparato de enforcement ao Estatuto da Metrópole, isto é, de um mecanismo capaz de garantir a aplicação dos instrumentos da lei (SANT’ANA, 2016, p. 120) e a promoção de ações setoriais de desenvolvimento urbano. A própria sanção de improbidade administrativa prevista no art. 21 (BRASIL, 2015) para os governadores ou agentes públicos que descumprissem algumas providências básicas, como, por exemplo, "elaborar e aprovar, no prazo de 3 (três) anos, o plano de desenvolvimento urbano integrado das regiões metropolitanas", foi revogada pela Lei n. 13.683, de 2018 (BRASIL, 2018).

Na mesma toada, conforme destacam Carolina Heldt D’Almeida e Bárbara Oliveira Marguti (2018, p. 290) em relação ao PDUI da RM de São Paulo, se houvesse uma avaliação estratégica melhor e planejada acerca das prioridades regionais, dos efeitos e das finalidades do interesse público, em vez de o PDUI se restringir a diretrizes e a uma simples listagem de propostas, o Estatuto da Metrópole poderia, certamente, ser aplicado com mais efetividade (enforcement) e garantiria um avanço da política metropolitana na viabilização de uma estrutura básica de governança interfederativa. Em relação ao complexo jogo de disputas de poder político, pode-se afirmar que, ao mesmo tempo que a participação popular e o envolvimento dos agentes econômicos da iniciativa privada podem colaborar para um processo de gestão mais aberto e participativo, são também elementos fragmentadores de poder e que, se não bem disciplinados, podem corroborar a fragilidade institucional e a complexidade do ato de governar as regiões metropolitanas.

Klaus Frey (2012, p. 91) destaca que um dos problemas mais sensíveis na condução das entidades regionais é a inclusão da dimensão popular, "por meio de mecanismos participativos efetivamente democráticos nos processos decisórios metropolitanos e regionais”.

Essa assertiva se agrava quando o Estatuto da Metrópole deixa de pormenorizar mecanismos de accountability que permitam a "construção de uma ação conjunta, transparente e compartilhada entre Estado, sociedade civil e pelas empresas (agentes do setor econômico)", visando à concretização de uma agenda de políticas públicas (SANT’ANA, 2016, p. 109). Ademais, falta a figura de uma identidade metropolitana de forma que a população tenha o "sentimento de pertencimento a uma unidade territorial que aglomera várias identidades municipais arraigadas no cerne da vida urbana” (idem, ibidem).

Deve-se explicitar que o enfoque da lei foi fortalecer a governança metropolitana, mas não disciplinou a possibilidade de gestão exclusiva das principais FPICs, como transporte, saneamento básico, resíduos sólidos e moradias, diretamente pelas unidades regionais ou por um ente federativo exclusivo, como uma 
secretaria estadual específica para a gestão da RM (para contraponto, ver ADI 1842/ $\mathrm{RJ})$. Considerando que se trata de atividades altamente complexas e que exigem conhecimentos técnicos profundos, além de montante de recursos, um corpo técnico específico para gerir essas FPICs poderia fortalecer a governança interfederativa (OLIVEIRA, 2015, p. 642).

De fato, para mostrar a importância da formação de um corpo técnico para enfrentar os desafios propostos pela governança regional, sobretudo diante da variedade das FPICs envolvidas e da necessidade de conhecimentos técnicos adequados, na Região Metropolitana de Salvador, Bahia, a equipe técnica local participou de diversos seminários em nível nacional para viabilizar a troca de experiências com outras regiões do país (RODRIGUES, 2018, p. 341). O objetivo era conseguir uma estruturação melhor de todo o sistema de governança local, baseando-se nas experiências das regiões metropolitanas de São Paulo, Rio de Janeiro e Minas Gerais.

É relevante que se diga que faltou também a lei disciplinar como seria uma compatibilização maior com o PDUI, ou mesmo com os planos diretores, dos chamados planos setoriais, como os que envolvem mobilidade urbana, saneamento, habitação, resíduos sólidos e uso do solo. Essa ausência torna o processo de gestão da região metropolitana ainda mais débil.

Isso se torna ainda mais evidente quando se observa que países como Itália, Portugal, Espanha, França e Alemanha, que apresentam um planejamento mais adequado, colocam em posição de destaque os planos urbanísticos em seus ordenamentos, especialmente os regionais. A Itália, por exemplo, conta com três planos fundamentais que dialogam bem entre si: um territorial de coordenação (regional); um de regulação geral (mais vinculado às cidades) e um de caráter privado e mais ligado às necessidades diretas do território abrangido por ele (bairro) (BONIZZATO, 2015, p. 1872).

Falta igualmente um sistema de informações metropolitanas para uma tomada de decisão mais subsidiada, uma vez que a Lei n. 13.683, de 2018 (BRASIL, 2018), revogou o Sistema Nacional de Desenvolvimento Urbano (SNDU), em que se assegurava "participação da sociedade civil e incluía um subsistema de planejamento e informações metropolitanas, coordenado pela União e com a participação dos Governos estaduais e municipais”, previsto no art. 20 do Estatuto da Metrópole. Esse fato torna ainda mais frágil o ambiente conturbado de gestão mais eficiente das regiões metropolitanas.

Diante desses pressupostos, quando se visualiza um modelo de governança interfederativa que melhor atenda ao contexto federativo brasileiro, marcado pela fragilidade institucional das regiões metropolitanas, devem ser levados em 
consideração mecanismos flexíveis de diálogo e construção horizontal (município-município) e vertical (município-estado) (PETERS, 2008), voltados para metas, projetos e instrumentos com foco na eficiência e na efetividade das políticas públicas, sob constante controle pela sociedade civil (participação), e para a superação de complexidades e fragilidades institucionais (SANT'ANA, 2016, p. 109).

Para tanto, são necessários mecanismos capazes de lidar com a fragmentação e a descentralização de poder e de viabilizar o ato de governar o território metropolitano, marcado pelo seu arranjo jurisdicional polinucleado (SANT'ANA, 2016, p. 106). Outro fator importante seria a criação de um ambiente político de cooperação, concertação, coordenação, planejamento, articulação, integração e execução de funções públicas entre os diversos níveis de governo, aliada à capacidade de pensar em um arranjo metropolitano que incluísse atores públicos e privados, além da sociedade civil organizada (ANDRADE, 2007) com a sua inserção no processo decisório das políticas públicas ou de ações. Essa perspectiva multinível de governança, inclusive, já tem sido alvo de debates e ganha notoriedade na Europa e nos Estados Unidos, enquanto, na América Latina, a governança metropolitana ainda se mantém atrelada a questões como otimização técnico-funcional do planejamento físico-territorial (FREY, 2012, p. 93).

Em face dessa multiplicidade de fatores essenciais ao bom andamento das unidades regionais, é necessário que se atenda a algumas metadimensões (SANT'ANA, 2016, p. 113-117), a saber:

a) Coordenação vertical: substituição do modelo de subordinação hierárquica para o modelo de subsidiariedade (nível superior + nível inferior), isto é, de parceria. Para tanto, deve haver "melhores fluxos de informação, divisão mais clara do trabalho e prestação de contas, e assegurar o consentimento no processo de tomada de decisão" (UNIÃO EUROPEIA, 2014, p. 17 - tradução livre);

b) Coordenação horizontal: com atuação voltada ao combate da fragmentação e da decorrente fragilidade ocasionadas pela abordagem setorizada das políticas públicas. É um desafio que exige estratégias e instrumentos políticos para o fortalecimento das gestões subnacionais e da governança interfederativa (com estratégias que vão além da melhor gestão das FPICs e da implementação do PDUI);

c) Integração interterritorial funcional: tentativa de integração de projetos, investimentos e iniciativas no âmbito territorial entre os diversos atores integrantes daquele território; 
d) Capacidade organizacional dos territórios: investimento no desenvolvimento de ferramentas e no fortalecimento dos atores integrantes do território. Foco no planejamento estratégico, no financiamento, na monitoração e avaliação de resultados;

e) Mobilização dos stakeholders (partes interessadas): participação de diversos atores, públicos e privados, de forma efetiva (participação substantiva), desde a formulação até a avaliação da política. De acordo com Gilberto Bercovici (2003, p. 147-149): “[...] num Estado federal a unidade é o resultado de um processo de integração, em que a autonomia não se limita a ser um objeto passivo (garantia), mas é, essencialmente, sujeito ativo na formação desta unidade estatal (participação)”.

Algumas medidas podem ajudar nesse longo caminho em busca de boa governança interfederativa, mesmo que várias delas não tenham sido adotadas pelo Estatuto da Metrópole: necessidade de uma instância exclusiva responsável por gerir somente a região metropolitana, além de instâncias setoriais exclusivas de gestão metropolitana para gerir as principais FPICs; de fundos operantes e alimentados com recursos destinados tanto ao planejamento e à gestão metropolitanos como a uma carteira de investimentos estruturais em projetos e em infraestrutura; de conselhos deliberativos e consultivos operantes; de maior participação nos orçamentos plurianuais de todos os atores envolvidos (compatibilização dos planos plurianuais, lei de diretrizes orçamentárias e orçamentos anuais dos entes envolvidos) e de diversidade e de quantidade significativa de articulações institucionais entre entes e atores para a governança (COSTA, 2013).

Diante desse quadro, torna-se necessário um modelo de governança interfederativa baseado na "formulação de políticas de desenvolvimento, fixação de diretrizes e avaliação de resultados em perfeita coordenação, tanto em linha vertical quanto em linha horizontal" (SCHIRATO, 2016). Vale acrescentar que as metas e diretrizes a serem adotadas devem pautar-se por um desenvolvimento econômico sustentável e que a atuação dos entes federativos (inclusive a União) deve ocorrer em parceria, entre eles e com a sociedade, "introduzindo políticas urbanas capazes de oferecer resultados gradualmente e apropriando-se das próprias experiências" (SANTOS, 2006).

\section{Considerações finais}

Durante o período de ditadura militar, as regiões metropolitanas eram associadas ao autoritarismo e à centralização da administração pública. Isso resultou no esvaziamento das competências tributárias e das políticas do município, ao 
mesmo tempo que as regiões metropolitanas eram utilizadas como um instrumento político de controle mais direto sobre a distribuição de recursos para essas áreas, na tentativa de amortecer as tensões sociais crescentes nos principais centros urbanos e de reduzir o poder decisório nas bases locais. Esse fato não ocorreu apenas no Brasil. Diversos países da América Latina, por muito tempo, associaram a gestão metropolitana a um processo de centralização e autoritarismo do governo central.

Com a CF-88, inaugurou-se uma nova fase do federalismo de cooperação com foco no municipalismo. Houve elevação dos encargos e responsabilidades com relação às políticas públicas e à prestação de serviços públicos, transferindo-os aos estados e municípios, mas sem o suficiente aporte de recursos financeiros. Ato contínuo, a ADI 1842/RJ decidiu que a gestão das FPICs deveria ser compartilhada entre o estado e os municípios envolvidos. Tais fatos, além de provocarem maior fragmentação dos processos de tomada de decisões, causando maior fragilidade institucional das regiões metropolitanas, tornaram mais complexa a gestão das funções públicas de interesse comum.

Para tentar superar a complexidade de governar e essa fragmentação do poder, realizada desarticuladamente e sem as devidas precauções para uma gestão integrada, o Poder Público cria uma região metropolitana. Contudo, na prática, ocorrem dificuldades com a gestão metropolitana em relação à cooperação entre os entes: fragilidade institucional, baixa cooperação entre os entes e poucos recursos financeiros para enfrentar a crescente demanda por funções públicas de interesse comum de grande complexidade.

Nesse cenário conturbado, surgiu o Estatuto da Metrópole, por intermédio da Lei federal n. 13.089, de 12 de janeiro de 2015, em que se estabeleceram diretrizes gerais para o planejamento, a gestão e a execução das funções públicas de interesse comum em regiões metropolitanas. Seu objetivo era criar mecanismos para melhor gerir e lidar com a integração econômica, política e cultural dentro da região metropolitana por meio de uma governança interfederativa. Buscou-se então constituir um quadro institucional propício à governabilidade das regiões metropolitanas diante da fragmentação do poder desses territórios e da própria complexidade de governar nessas regiões, reforçando a necessidade de cooperação entre os entes federativos.

Apesar de trazer instrumentos necessários, a exemplo da gestão plena e do PDUI, a lei não abarcou pontos essenciais, como a gestão exclusiva de funções públicas de interesse comum, a forma de integração e de compatibilização dos planos setoriais com os planos diretores e com o PDUI; faltou, principalmente, a instituição 
de fundos de grande capacidade (o que foi vetado pelo governo), necessários para a boa gestão das FPICs, comprometendo muito a boa governança interfederativa.

Portanto, em um contexto federativo brasileiro com fragmentação do poder, complexidade de governar e de fragilidade institucional das regiões metropolitanas, um modelo de governança interfederativa deve abarcar instrumentos mais fluidos e flexíveis de diálogo e integração dos entes federativos envolvidos voltados para metas e resultados, sob o crivo constante da sociedade civil. Nesse sentido, para ter boa governança interfederativa, as metadimensões devem ser respeitadas: coordenação vertical; coordenação horizontal; integração interterritorial funcional; capacidade organizacional dos territórios e mobilização dos stakeholders.

É importante entender o "espaço metropolitano" e a real necessidade de melhor integração entre municípios conurbados e o estado para a indução de uma gestão associada de serviços públicos mais efetiva. Não se quis neste estudo reduzir a importância do Estatuto da Metrópole; o que se pretendeu foi mostrar que a governança metropolitana sólida, eficiente e bem articulada, capaz de fomentar o desenvolvimento sustentável das regiões metropolitanas, não pode ser refém de disputas políticas e de poder em um ambiente de competição desnecessária, mas deve sempre ser pautada por condutas com base na boa administração, na execução adequada das funções públicas de interesse comum e no atendimento das necessidades da população regional. Quando há disputas entre estado e município, quem perde é a população que carece desses serviços (GALLACCI, 2015). Como diz o ditado popular: "na briga entre o rochedo e as ondas, quem perde é o marisco".

\section{Referências}

ALFONSO ROA, Ó. A. Regiones Metropolitanas de Colômbia: la gravitación e la desarticulación como razgos dominantes de la organización territorial en curso. Revista Cadernos Metrópole, v. 19, n. 40. São Paulo, set.-dez. 2017, p. 919-949. Disponível em: http://dx.doi. org/10.1590/2236-9996.2017-4010. Acesso em: 2 de fev. 2020.

ALVES, A. C. Regiões metropolitanas, aglomerações urbanas e microrregiões: novas dimensões constitucionais da organização do Estado brasileiro. Revista de Direito Ambiental, v. 6, n. 21. São Paulo, 2001, p. 57-82. Disponível em: http://www.pge.sp.gov.br/centrodeestudos/revistaspge/revista/tes1.htm. Acesso em: 10 ago. 2018.

ANDRADE, I. A. L. de; CLEMENTINO, M. do L. M. Descentralização e impasses da governança. In: RIBEIRO, L. C. de Q.; SANTOS JUNIOR, O. A. dos (orgs.). As metrópoles e a questão social brasileira. Rio de Janeiro: Fase, 2007.

BARROSO, L. R.. Saneamento básico: competências constitucionais da União, estados e municípios. Redae - Revista Eletrônica de Direito Administrativo Econômico, n. 11. Salvador, out. 2007. Disponível em: http://www2.senado.leg.br/bdsf/item/id/762. Acesso em: 10 ago. 2018. 
BERCOVICI, G. Desigualdades regionais, estado e constituição. São Paulo: Max Limonad, 2003.

BONIZZATO, L. O Estatuto da Metrópole e novas esperanças para o futuro da política de planificação e planejamento no Brasil: o Plano de Desenvolvimento Urbano Integrado. Revista de Direito da Cidade, v. 7, n. 4. Rio de Janeiro: Uerj, 2015, p. 1864-1887. Disponível em: https://www.e-publicacoes.uerj.br/index.php/rdc/article/view/20917. Acesso em: 10 fev. 2020.

BRUNO, R. M. Regiões Metropolitanas: posição no cenário constitucional, competência e financiamento de suas atividades no Estado brasileiro. Curitiba: Juruá, 2016.

CÉSAR, P. S. M. Competências constitucionais do sistema federativo envolvendo funções públicas de interesse comum em regiões metropolitanas. Interações, v. 18, n. 3. Campo Grande, MS, jul.-set. 2017, p. 141-157. Disponível em: http://www.interacoes.ucdb.br/ article/view/1447. Acesso em: 10 ago. 2018.

CÉSAR, P. S. M.; SOUZA, D. F. de; SILVA, F. A. e; ALMEIDA, G. H. M. D. A gestão das Funções Públicas de Interesse Comum em Regiões Metropolitanas: o caso da Região Metropolitana de Belo Horizonte. Congresso Virtual Brasileiro - Administração, v. 5. 2016. Disponível em: http://www.convibra.com.br/upload/paper/2016/38/2016_38_13372.pdf. Acesso em: 10 ago. 2018.

CLEMENTINO, M. do L. M. A (não) implementação do Estatuto da Metrópole na Região Metropolitana de Natal. In: MARGUTI, B. O.; COSTA, M. A.; FAVARÃO, C. B. (orgs.). Brasil metropolitano em foco: desafios à implementação do Estatuto da Metrópole. v. 4. Brasília: Ipea, 2018, p. 367-390. Disponível em: http://www.ipea.gov.br/portal/images/stories/ PDFs. Acesso em: 2 fev. 2020.

COSTA, M. A.; TSUKUMO, I. T. L. (org.). 40 anos de Regiões Metropolitanas no Brasil. v. 1. Série Rede Ipea. Projeto Governança Metropolitana no Brasil. Brasília, 2013. Disponível em: http://www.ipea.gov.br/redeipea/images/pdfs/governanca_metropolitana/livro_40_ anos_de_regioes_metropolitanas_v1_web.pdf. Acesso em: 3 out. 2018.

COSTA, M. A.; FAVARÃO, C. B.; TAVARES, S.; BLANCO JUNIOR, C. Do processo de metropolização institucional à implementação do Estatuto da Metrópole: dois balanços, suas expectativas e incertezas. In: MARGUTI, B. O.; COSTA, M. A.; FAVARÃO, C. B. (orgs.). Brasil metropolitano em foco: desafios à implementação do Estatuto da Metrópole. v. 4. Brasília: Ipea, 2018, p. 19-54. Disponível em: http://www.ipea.gov.br/portal/images/ stories/PDFs. Acesso em: 2 fev. 2020.

D’ALMEIDA, C. H.; MARGUTI, B. O. A elaboração do plano e da governança da Região Metropolitana de São Paulo: premissas e escopo, metas e método, estratégias e resultados da primeira fase do processo. In: MARGUTI, B. O.; COSTA, M. A.; FAVARÃO, C. B. (orgs.). Brasil metropolitano em foco: desafios à implementação do Estatuto da Metrópole. v. 4. Brasília: Ipea, 2018, p. 267-296. Disponível em: http://www.ipea.gov.br/portal/images/ stories/PDFs. Acesso em: 2 fev. 2020.

FREY, K. Abordagens de governança em áreas metropolitanas da América Latina: avanços e entraves. Revista Brasileira de Gestão Urbana, v. 4, n. 1. jan.-jun. 2012, p. 87-102. Disponível em: http://dx.doi.org/10.1590/S2175-33692012000100007. Acesso em: 2 fev. 2020. 
GALLACCI, F. B. Reflexão acerca das disputas jurídicas envolvendo o setor de saneamento brasileiro. Revista de Direito Administrativo Contemporâneo, v. 21. São Paulo: RT, nov.-dez. 2015.

GUIA, V. R. dos M. Estudos básicos para a RMBH: subsídios para o plano de desenvolvimento. Tema Transversal - Gestão Metropolitana. Belo Horizonte: Fundação João Pinheiro, 2006.

HORTA, R. M. Direito Constitucional Brasileiro e as regiões metropolitanas. Revista de Informação Legislativa, v. 12, n. 46. Brasília, abr.-jun. 1975, p. 33-42. Disponível em: http://www2.senado.leg.br/bdsf/handle/id/182005. Acesso em: 15 ago. 2018.

LOUREIRO, V.; LEITE, V. F. e. Por uma região metropolitana eficiente, equilibrada e sustentável - contribuição da Câmara Metropolitana de Integração Governamental do Estado do Rio de Janeiro. In: MARGUTI, B. O.; COSTA, M. A.; FAVARÃO, C. B. (orgs.). Brasil metropolitano em foco: desafios à implementação do Estatuto da Metrópole. v. 4. Brasília: Ipea, 2018, p. 241-266. Disponível em: http://www.ipea.gov.br/portal/images/stories/ PDFs. Acesso em: 2 fev. 2020.

MACHADO, G. G.; SOUKI, L. G.; FARIA, C. A. P. Processo legislativo, articulação intergovernamental e gestão metropolitana: inovação institucional e participação social na Região Metropolitana de Belo Horizonte. XIII Congresso Brasileiro de Sociologia - GTo2: Cidades e processos sociais, v. 1. Recife: SBS, 2007.

MARGUTI, B. O.; COSTA, M. A. Análise da gestão e da governança metropolitanas das Funções Públicas de Interesse Comum selecionadas. In: COSTA, M. A.; MARGUTI, B. O. (orgs.). Funções públicas de interesse comum nas metrópoles brasileiras: transportes, saneamento básico e uso do solo. Brasília: Ipea, 2014, p.15-46. Disponível em: https://www. ipea.gov.br/portal/index.php?option=com_content\&view=article\&id=24031. Acesso em: 30 jan. 2020.

OLIVEIRA, N. S. de. Estatuto da Metrópole: reflexões acerca do instituto legal e da governança metropolitana. XXIV Congresso Nacional do Conpedi - UFMG/Fumec/Dom Helder Câmara. Belo Horizonte, MG, 2015, p. 626-648. Disponível em: http://conpedi.danilolr. info/publicacoes/66fsl345/mq42p84j/lzQeLQAQYHQ2yz11.pdf. Acesso em: 10 ago. 2018.

ONU-HABITAT. Programa de Las Naciones Unidas para los asentamientos urbanos - ONUHabitat. Estado de las ciudades de América Latina y el Caribe 2012: rumbo a uma nueva transición urbana. ONU, 2012. Disponível em: http://estaticog1.globo.com/2012/08/21/Estado-de-las-Ciudades-de-America-Latina-y-el-Caribe-2012.pdf. Acesso em: 29 jan. 2020.

PERES, J. L. P. et al. . O Estatuto da Metrópole e as regiões metropolitanas: uma análise teórico-conceitual à luz do conceito miltoniano de "território usado". Revista Cadernos Metrópole, v. 20, n. 1. São Paulo, jan.-abr. 2018, p. 267-288. Disponível em: https://revistas. pucsp.br/metropole/article/view/2236-9996.2018-4113/25193. Acesso em: 31 jan. 2020.

PETERS, B. G. Os dois futuros do ato de governar: processos de descentralização e recentralização no ato de governar. Revista do Serviço Público, v. 59, n. 3. Brasília: Enap, p. 289-307, jul.-set. 2008. Disponível em: https://revista.enap.gov.br/index.php/RSP/article/ view/151. Acesso em: 5 out. 2018. 
RODRIGUES, M. A. dos S. et al. . Os caminhos do planejamento e da governança da Região Metropolitana de Salvador: entre o ser e o dever ser - afirmação jurídica e controvérsia política. In: MARGUTI, B. O.; COSTA, M. A.; FAVARÃO, C. B. (orgs.). Brasil metropolitano em foco: desafios à implementação do Estatuto da Metrópole. v. 4. Brasília: Ipea, 2018, p. 323-346. Disponível em: http://www.ipea.gov.br/portal/images/stories/PDFs. Acesso em: 2 fev. 2020.

ROJAS, E. Governança de Regiões Metropolitanas da América Latina. Texto apresentado no UrbanEdge. São Paulo, dez. 2008. Disponível em: https://emplasa.sp.gov.br/Cms_Data/ Sites/EmplasaDev/Files/fnem/Arquivos/Bid/. Acesso em: 28 jan. 2020.

SALEME, E. R.; CARRIÇO, J. M. (orgs.). Comentários ao Estatuto da Metrópole. Santos, SP: Editora Universitária Leopoldianum, 2018.

SANT’ANA, M. C. Estatuto da Metrópole: limites e possibilidades dos instrumentos e estratégias de planejamento e gestão urbana da Lei n. 13.809, de 2015. Meridiano - Revista de Geografia, n. 5. 2016, p. 93-124. Disponível em: http://www.revistameridiano.org. Acesso em: 10 ago. 2018.

SANTOS, B. S. dos. Federalismo e desenvolvimento urbano. Cadernos Unifoa, v. 1. 2006, p. 55-70.

SCHIRATO, R. N. M. Estatuto da Metrópole: uma análise jurídica preliminar. Revista de Direito Administrativo Contemporâneo, v. 22. São Paulo: RT, jan.-fev. 2016.

UNIÃO EUROPEIA. Comissão Europeia. Direção-geral para Política Regional e Urbana. Inception Report: Study on Promoting Multi-level Governance in Support of Europe 2020. Bruxelas: União Europeia, 2014. Disponível em: http://www.qren.pt/np4/np4/?newsId=4187\&fileName=mlg_inception_report_20140114.pdf. Acesso em: 5 out. 2018.

Legislação

BRASIL (1967). Constituição da República Federativa do Brasil de 1967. Brasília: DOU, 1967. Disponível em: http://www.planalto.gov.br/ccivil_03/constituicao/constituica067.htm. Acesso em: 10 fev. 2020.

(1969). Emenda Constitucional $n^{o} 1$ de 1969. Brasília: DOU, 1969. Disponível em: http://www.planalto.gov.br/ccivil_03/constituicao/Emendas/Emc_anterior1988/emc0169.htm. Acesso em: 10 fev. 2020.

(1988). Constituição da República Federativa do Brasil de 1988: texto constitucional promulgado em 5 de outubro de 1988. Brasília: DOU, 1988. Disponível em: http://www. planalto.gov.br/ccivil_03/constituicao/constituicao.htm. Acesso em: 10 fev. 2020.

(1973). Lei Complementar 14 de 1973. Estabelece as regiões metropolitanas de São Paulo, Belo Horizonte, Porto Alegre, Recife, Salvador, Curitiba, Belém e Fortaleza. Brasília: DOU, 1973. Disponível em: http://www.planalto.gov.br/ccivil_03/leis/lcp/Lcp14.htm. Acesso em: 10 fev. 2020.

(2001). Lei n. 10.257 de 2001. Institui o Estatuto da Cidade que estabelece diretrizes gerais da política urbana. Brasília: DOU, 2001. Disponível em: http://www.planalto.gov. br/ccivil_03/leis/leis_2001/110257.htm. Acesso em: 10 fev. 2020. 
BRASIL (2015). Lei n. 13.089 de 2015. Institui o Estatuto da Metrópole, altera Lei n. 10.257 de 10 de julho de 2001, e dá outras providências. Brasília: DOU, 2015. Disponível em: http://www.planalto.gov.br/ccivil_03/_ato2015-2018/2015/lei//13089.htm. Acesso em: 10 fev. 2020.

(2018). Lei $n^{\circ} 13.683$ de 2018. Altera as Leis $n^{0} 13.089$, de 12 de janeiro de 2015 (Estatuto da Metrópole), e 12.587, de 3 de janeiro de 2012, que institui as diretrizes da Política Nacional de Mobilidade Urbana. Brasília: DOU, 2018. Disponível em: http://www.planalto. gov.br/ccivil_03/_Ato2015-2018/2018/Lei/L13683.htm. Acesso em: 10 fev. 2020.

Acórdão

BRASIL. SUPREMO TRIBUNAL FEDERAL. ADI 1842/RJ. Relator ministro Luiz Fux. Publicado no DJe em: 19 fev. 2019. Disponível em: http://portal.stf.jus.br/processos/detalhe.asp?incidente $=1714588 \#$ decisoes. Acesso em 28 jan. 2020. 


\section{Rodrigo Rage Ferro}

Doutorando em Direito da Universidade Católica de Santos (Unisantos). Mestre em Direito pela Escola Paulista de Direito (EPD). Formado em Direito e em Engenharia de Computação, ambos pela Universidade de São Paulo (USP). Também cursou um ano de graduação, como intercâmbio, em Direito (Juristische Fakultät) na universidade alemã Eberhard Karls Universität Tübingen.

Email: roragferro@gmail.com

ORCID: 0000-0001-8742-8496

Contribuição de autoria: escrita, revisão e edição.

\section{Edson Ricardo Saleme}

Pós-doutor em Direito pela Universidade Federal de Santa Cataria (UFSC). Doutor em Direito de Estado pela Universidade de São Paulo (USP). Professor do curso stricto sensu em Direito Ambiental Internacional da Universidade Católica de Santos (Unisantos). Participante da Sociedade Civil da Região Metropolitana da Baixada Santista, consultor do Ibama e professor da Escola Superior da Magistratura de São Paulo.

Email: ricasal@uol.com.br

ORCID: 0000-0002-9533-0031

Contribuição de autoria: escrita, revisão e edição.

Submissão: 18 de março de 2019.

Aprovação: 25 de março de 2020.

Como citar: FERRO, R. R.; SALEME, E. R. A fragmentação do poder e a complexidade de governar nas regiões metropolitanas. Revista brasileira de estudos urbanos e regionais. v. 22, E202012, 2020. DOI 10.22296/2317-1529.rbeur.202012

Artigo licenciado sob Licença Creative Commons CC BY-NC 4.0.

https://creativecommons.org/licenses/by-nc/4.o/deed.pt_BR 